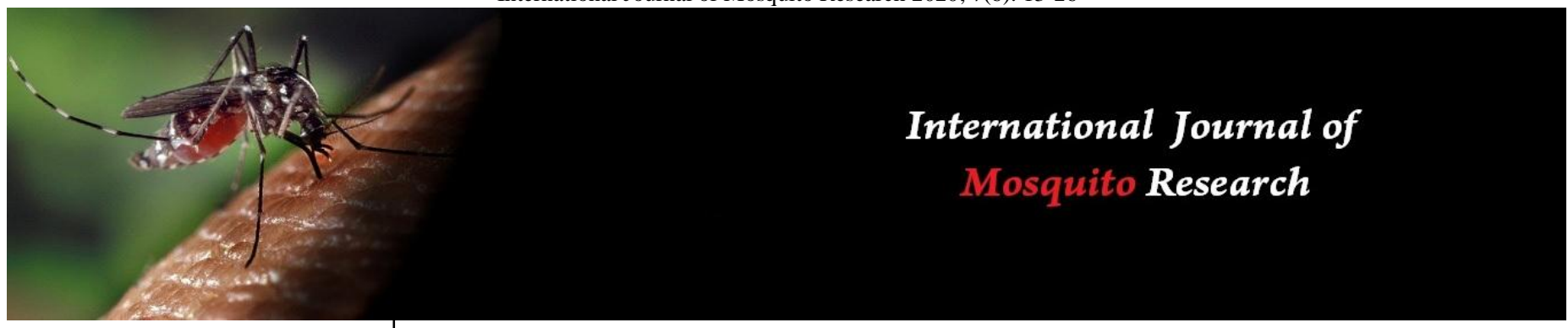

ISSN: 2348-5906

CODEN: IJMRK2

IJMR 2020; 7(6): 13-26

(C) $2020 \mathrm{IJMR}$

Received: 11-09-2020

Accepted: 13-10-2020

\section{Ashwini M}

Department of Microbiology,

Faculty of Life Sciences, JSS

Academy of Higher Education and Research, Sri

Shivarathreeshwara Nagar,

Mysuru, Karnataka, India

Talluri Rameshwari KR

Department of Microbiology,

Faculty of Life Sciences, JSS

Academy of Higher Education

and Research, Sri

Shivarathreeshwara Nagar,

Mysuru, Karnataka, India

\section{Sumana MN}

Department of Microbiology, JSS Medial College and Hospital, JSS Academy of Higher

Education and Research, Sri

Shivarathreeshwara Nagar,

Mysuru, Karnataka, India

\section{Dr. Sumana K}

Assistant professor, Department of Microbiology, Faculty of

Science, JSS Academy of Higher Education \& Research, Mysuru,

Karnataka, India
Corresponding Author:

\section{Dr. Sumana K}

Assistant professor, Department of Microbiology, Faculty of Science, JSS Academy of Higher Education \& Research, Mysuru, Karnataka, India

\section{GIS-Based analysis of the spatial distribution of dengue disease in Mysuru district and India, 2013-2018}

\author{
Ashwini M, Talluri Rameshwari KR, Sumana MN and Dr. Sumana K
}

DOI: https://doi.org/10.22271/23487941.2020.v7.i6a.484

\begin{abstract}
Background and Objective: The dengue disease has become growing menace in the public health concern due to its re-emergence in tropical and subtropical regions. To understand the epidemiology and spatial distribution, a retrospective surveillance study was conducted in Mysore district of Karnataka and India for the year 2013 to 2018 .

Methods: A comprehensive data about dengue infection, prevalence, transmission and severity in 8 taluks of Mysore district of Karnataka and 35 states of India were mapped through Arc/Geographic Information System (GIS) software. Spatial statistical analysis was performed to identify hot spots and cold spots of dengue disease. Similarly, inverse distance weight (IDW), a spatial autocorrelation tool was also applied to understand the endemicity patterns in the study area.

Results: The analysis revealed that Mysore district and India had an increased rate of re-emerging dengue cases during the year 2017 and 2018. The use of GIS software revealed the number of incidences, high and low clustered areas, hotspot and cold spot locations of the registered dengue cases. The IDW tool was used to identify the disease intensity in Mysore district and India. Mysore city stood highest in the district and the lowest clustered area was found to be HD Kote in 2018. Karnataka (17018) stood the third-highest and Arunachal Pradesh (15) stood lowest clustered area in India during 2017. The spatial autocorrelation was projected in the geographical space. Based on the disease, registered case intensity the taluks were characterized into high, average and low endemic areas.

Conclusion: The study indicated that socio-economic and socio-cultural variables are highly correlated with the prevalence of Dengue. This visualization approach, IDW-GIS helps the public health officials to identify the zones of disease endemics in executing real-time decisions for preventive and precautionary strategies to control the prevalence of "Dengue-the vector-borne" disease effectively.
\end{abstract}

Keywords: Dengue fever, geographic information system-arc gis, incidence of dengue cases in mysore district, spatial interpolation analysis

\section{Introduction}

Dengue fever, an acute viral illness is a major cause of the death of millions of people every year. World Health Organization estimated that around 50 to 100 million of dengue infections occur annually, thereby increasing the global incidence with a 30-fold over the past fifty years [41]. Currently, two-fifths of the overall world's population poses dengue virus infection that is a major menace to global public health ${ }^{[16]}$. The dengue fever also called Break bone fever caused by the Virus that belong to the genus Flavivirus and family Flaviviridae. Dengue virus is a single-stranded RNA virus that includes four different serotypes i.e., DEN-1, DEN-2, DEN-3 and DEN- $4^{[1-3]}$. The four serotypes of Dengue share common ecological and geographical niche. Dengue haemorrhagic fever (DHF) and Dengue fever are the clinical manifestations causing a wide spectrum of illness ${ }^{[3-5]}$. A mosquito, Aedes aegypti is a vector for dengue virus and hence a vector-borne disease that presents a major challenge to global health officials. However, the infection, transmission, diverse in manifestation and pathogenicity is the exaggeration for the stiff challenge to public health.

The dengue epidemiology in India has been very complex and significantly changed over almost the past six decades in terms of prevailing strains, the severity of disease and geographical locations that were affected ${ }^{[6]}$. According to WHO, around 96 million were affected with dengue fever in the year 2010, globally over 500000 people with dengue fever estimated to be hospitalized of which $2.5 \%$ died due to severity of the disease ${ }^{[7]}$. 
The widespread of dengue disease outbreak is observed in the major cities of India. Karnataka (17018) stood the thirdhighest and Arunachal Pradesh ${ }^{[15]}$ stood lowest clustered area in India. There was an increased rate of dengue reported cases 129166 to 157220 in the year 2016 to 2017 . However, the number reduced to 101192 in the year 2018 which is probably due to better patient management, better reporting and also increased diagnostic proficiencies ${ }^{[8]}$.

The study of spatial distribution, patterns and determinants of dengue in the Indian subcontinent is very complex and varies over the period. As most of the dengue cases were reported from cities, it was assumed that the dengue fever as the urban disease. However, the major outbreaks of dengue disease were found to be from the rural areas of western and southern India ${ }^{[9,10]}$. In 2017 , an outbreak of dengue epidemic in the country was 157220 cases and 250 deaths which were about $15-20 \%$ higher than the previous years. Five states of the country recorded a large number of dengue cases out of which Karnataka state ranked third in a total number of dengue positive cases ${ }^{[8]}$. In Mysore district, the endemic level of Dengue fever has altered the rate of disease and the magnitude of incidence in the last few years. The epidemiological conditions of the dengue disease that influence the transmission of the virus from the Aedes aegypti is the major cause for the dramatic emergence of dengue fever.

In recent years, with new interest and concern, the combination of climatic changes and the availability of various research tools has led an investigation on vector-borne disease. Spatial information techniques such as GIS (Geographic Information System) allows identifying the history of medical data in the field of the particular region affected by the disease ${ }^{[11,12]}$. However, applications of these techniques to study the spread of dengue are still limited to few studies and geographically limited to Mysore district. With GIS, the precision of dengue disease mapping concerning the Mysore locality can be intensified. Therefore, before mapping response to disease outbreak can be monitored and detected using GIS tools ${ }^{[13-15]}$.

The exclusive exploitation of disease incidence rate to monitor disease occurrence provide limited results. Therefore, the spatial distribution of dengue fever using tools of GIS assist to explore the frequency, intensity and duration of the dengue cases in Mysore district. Based on the analyses, a region with the highest cases can be identified as the source of Dengue fever.

The current study uses GIS tool and statistical analysis to locate the spatial distribution, hotspots and intensity of the incidence at the province. The support of GIS- tool aids in finding the dengue reported cases and targets the intensity hotspot distribution. The Arc-GIS is the software that includes Arc-Map, Arc-Catalog and Arc-toolbox. The software provides increasing levels of functionality and favours to discover spatial sodality patterns ${ }^{[36]}$. This tool was used to visualize and describe the spatial distribution of dengue reported cases. The use of GIS tool aids to identify the region at highest risk for the dengue fever outbreak at Mysore district. The dynamics and distribution of dengue fever ensued from the outcome of the result can be used as an indicator of hazard in a locality ${ }^{[17]}$.

\section{Materials and Methods \\ 2.1. Study area}

The southern part in the state Karnataka is Mysore District formally called as Mysuru, located at the Chamundi foothills. The geographical scale of the district Mysuru is $12^{\circ} 18^{\prime} 26^{\prime \prime}$ North latitude and $76^{\circ} 38^{\prime}$ 59" East longitude. The altitude being $24,427 \mathrm{ft}(739.7 \mathrm{~m})$. Mysore City Corporation is the headquarters of the Mysore district has also taken complete responsibility of civic administration of the city. Karanji Lake is the biggest 'Walk-Through Aviary' in the Mysore district. The land area used for residential, roads, industrial, public property, commercial agriculture, water, parks and open spaces during 2001 was $39.9 \%, 16.1 \%, 13.48 \%, 8.96 \%$, $3.02 \%, 2.27 \%, 2.02 \%$ and $13.74 \%$ respectively. During March to June summer season, July to November monsoon season, December to February winter season are the main seasons seen. On $4^{\text {th }}$ April 1917, the highest temperature 39.4 ${ }^{\circ} \mathrm{C}\left(103{ }^{\circ} \mathrm{F}\right)$ and on $16^{\text {th }}$ January 2012 the lowest temperature $7.7{ }^{\circ} \mathrm{C}\left(46{ }^{\circ} \mathrm{F}\right)$ was recorded. The city's average annual rainfall is $804.2 \mathrm{~mm}$ (31.7 in) (Fig. 1).

In 2011, Mysore had population of 3,001,127 of which male and female were 1,511,600 and 1,489,527 respectively. In 2001 census, Mysore had a population of 2,641,027 of which males were 1,344,670 and remaining 1,296,357 were females, making it the third-most populous city in Karnataka.

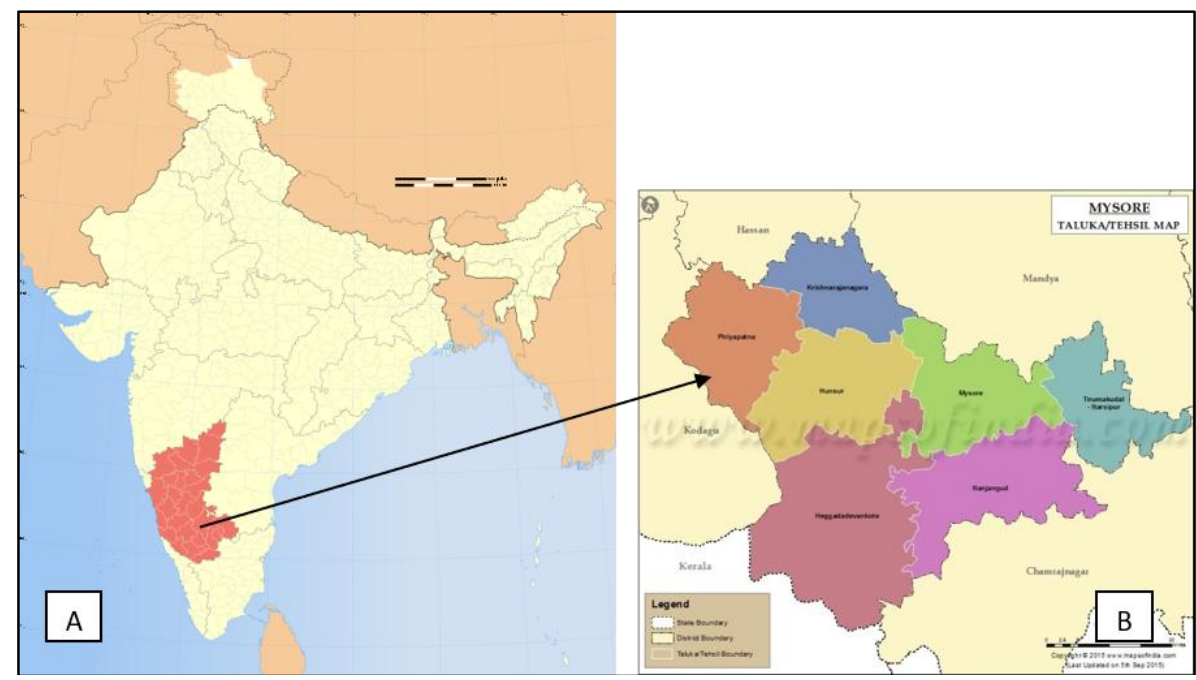

Fig 1: Study region focuses on India (A) and Mysore district (B) 


\subsection{Epidemiological data}

The epidemiological data on dengue cases was obtained from the District Health and Family Welfare Office, Government of Karnataka, Mysore for the period 2013-2018, which consists of information on dengue reported cases belonging to all the talukas of Mysore district. The sampling unit in the study is an individual household. All dengue patients were taken as sample and an equal number of randomly-selected unaffected samples in the study area were also included.

\subsection{GIS modelling with social data}

The extension of the use and analysis of the traditional paper map was used to develop GIS. The digital map data displayed on paper maps are the most basic form that uses measurement frameworks, and representation methods such as colours and classification schemes ${ }^{[18,19]}$.

The spatial data in a GIS is the first key component. Spatial and Relational Data Models are the central machinery of GIS. A digital format was used to capture Map data. The terminology layer was used to set individual features within spatial data in Arc-GIS. The GIS operator records the attribute data and digitizing of the coordinate data within a relational database of each feature table. An individual road segment within the spatial part of the layer and individual record within the tabular part of the layer has one to one relationship between them ${ }^{[20]}$

The coordinate features and the database table are the two parts of the layer. The functionality of the layer in the GIS requires both parts of the layer. The layer's attribute table records every city point in the spatial part of the layer. The linkage within layers between the tabular and spatial data of features allows the "what" and "where" questions in the GIS. The Arc-GIS software automatically manages this linkage.

This includes the confirmed Dengue cases notified from 2013-18 in Mysore District. The report is based on the data collected annually from all Taluks of Mysore. To obtain the spatial distribution of dengue using GIS-based analysis, the number of dengue cases were mapped at 1:25,000 scale by using a GIS technique in Arc-GIS software 10.2.2 (Demo Version).

\subsection{Arc- GIS Software 10.2.2 (Demo Version)}

Available interpolation options: Arc-GIS spatial analyst (version 10.2.2) comprises several interpolation tools for constructing surface grids from point data. One of the selected methods like:

IDW - The sample points are weighted during interpolation in the IDW interpolation method.

The influence was of one-point comparative to other descents with distance from the unknown point that has to be generated.

Spline - The values are estimated using a mathematical function in the Spline interpolation method. The surface curvature is minimized to a smooth surface that exactly passes through the input points.

Kriging - It is an effective type of spatial interpolation method. The values of unknown points based on the values at known points are estimated using complex mathematical formulae.

\subsection{Data analysis}

\subsubsection{Hotspot detection}

The different spatial clustering pattern such as hot spots, cold spots and high risk over the entire study area with statistical significance was identified using Getis-Ord 'Gi' statistics. The Z-score and p-value are the resultant that features high (hotspot) and low (coldspot) values cluster spatially. In comparison to a hotspot and low spot areas at high risk can be significantly identified ${ }^{[21]}$. With the defined distance band option or threshold limit the spatial relationship is fixed distance to analyse the hotspot. The peak $\mathrm{Z}$ value, the highest spatial autocorrelation exhibited by distance band is taken for the analysis. Keeping distance band option stable, each feature within the context of neighbouring features and specified distance band, a conceptual model of spatial interactions are executed. The spatial interpolation study aids to identify the geographical location of cold and hotspots of dengue cases that facilitate evidence to enable the policy decisions ${ }^{[21-23]}$.

\subsubsection{Spatial Analysis}

The process of extracting meaning and new information from the original data by manipulation of spatial information is called Spatial analysis. This study was carried out with a Geographic Information System (GIS). The statistical features and data interpolation geo-processing activities were calculated using the spatial analysis tools provided by the software GIS [24]. The hydrological modelling and the prominence of terrain analysis were emphasized in hydrology. The analytical functions that deals with wildlife point locations and their relationship with the environment were accentuated in wildlife management. Different user will have different things that they are interested in depending on the kind of work they do ${ }^{[25,26]}$.

Using point samples, the spatial point data of each house and surfaces were created by linking the household under the risk category. The results were produced by employing the inverse distance weighing (IDW) interpolation, the nearest neighbour technique ${ }^{[21,27]}$. The IDW interpolator assumes that the local influence on each input point diminishes with distance. A specified number of points within a specified radius can be used to determine the output value for each location ${ }^{[28,29]}$. The values to each cell were interpolated in the output grid theme by taking the average of the analysed value of each point by the distance using IDW interpolation ${ }^{[24]}$.

The detection of disease dengue spatial patterns are dived into two types: Local detection and Global detection by Standardized Mortality Ratios spatial patterns using GIS 10.2.2 software (Demo Version). The degree of homogenous attributes was accessed by acclamation of spatial autocorrelation by observing certain location and its neighbour units ${ }^{[22,23,30]}$.

\section{Results}

Mapping the distribution of dengue cases in a geographic area allows instant visual identification of areas that are at risk and facilitates faster conscription of resources. Fig. 2 shows total positive dengue cases in INDIA from the year 2010 to 2018. The overall dengue cases of 35 states of India in state-wise distribution (2010 to 2018) are illustrated in Fig. 3. 


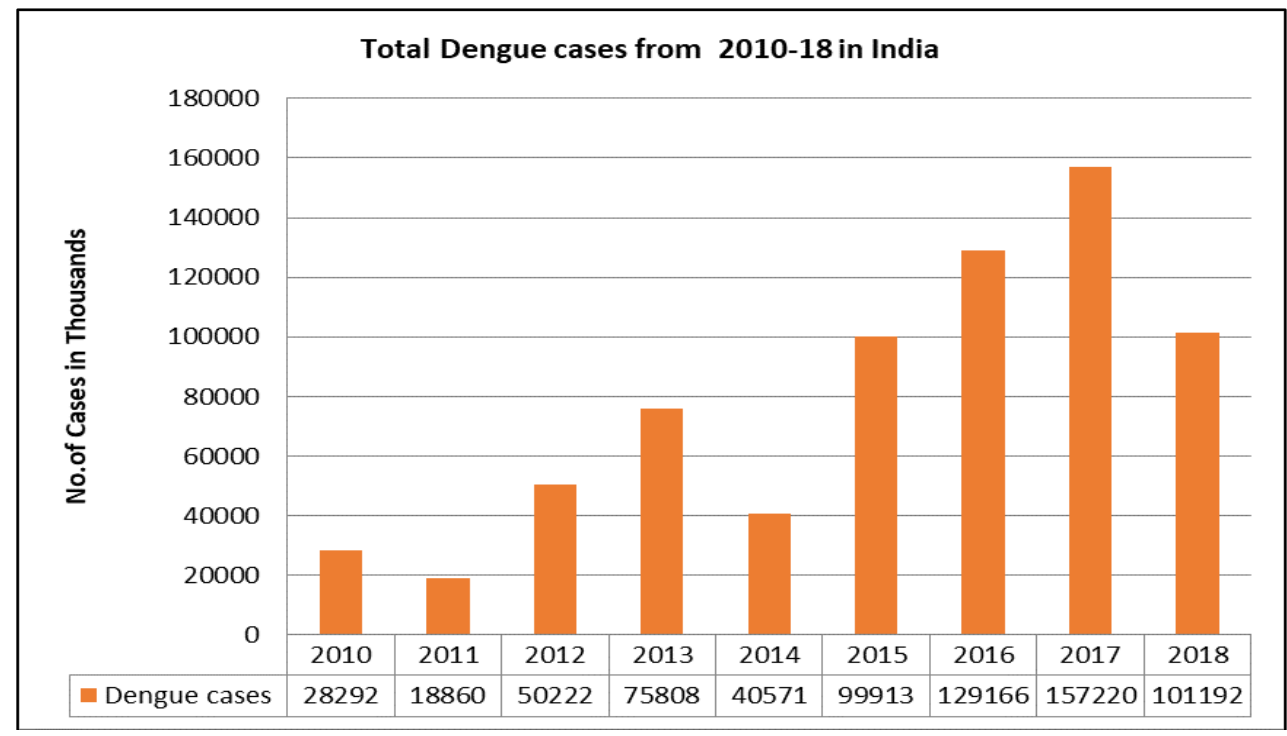

Fig 2: The total Dengue cases in India from 2010-18, year-wise distribution

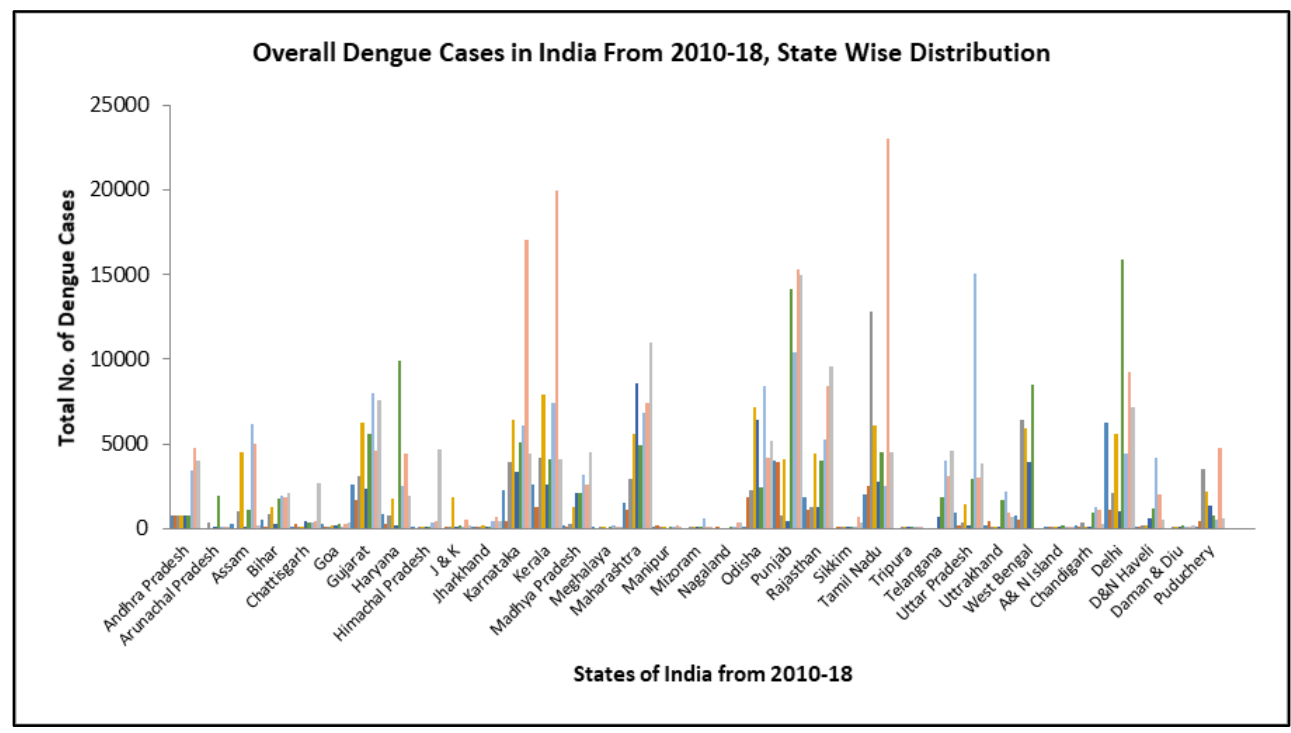

Fig 3: The Overall Dengue cases in India from 2010-18, Year wise distribution

The study interprets increased rate of re-emerging dengue cases during the year 2017. The dengue death cases, year wise distribution and state wise distribution in INDIA from 2010 to
2018 is illustrated graphically in Fig. 4 and Fig. 5 respectively.

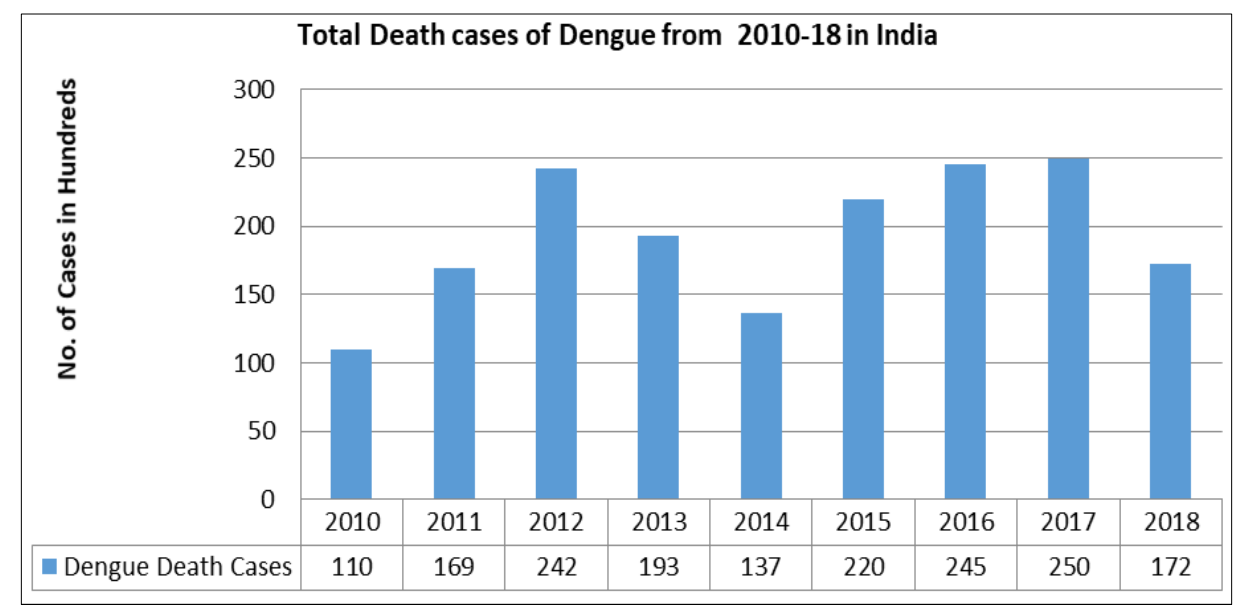

Fig 4: The Total Dengue Death Cases in India from 2010-18, year-wise distribution 


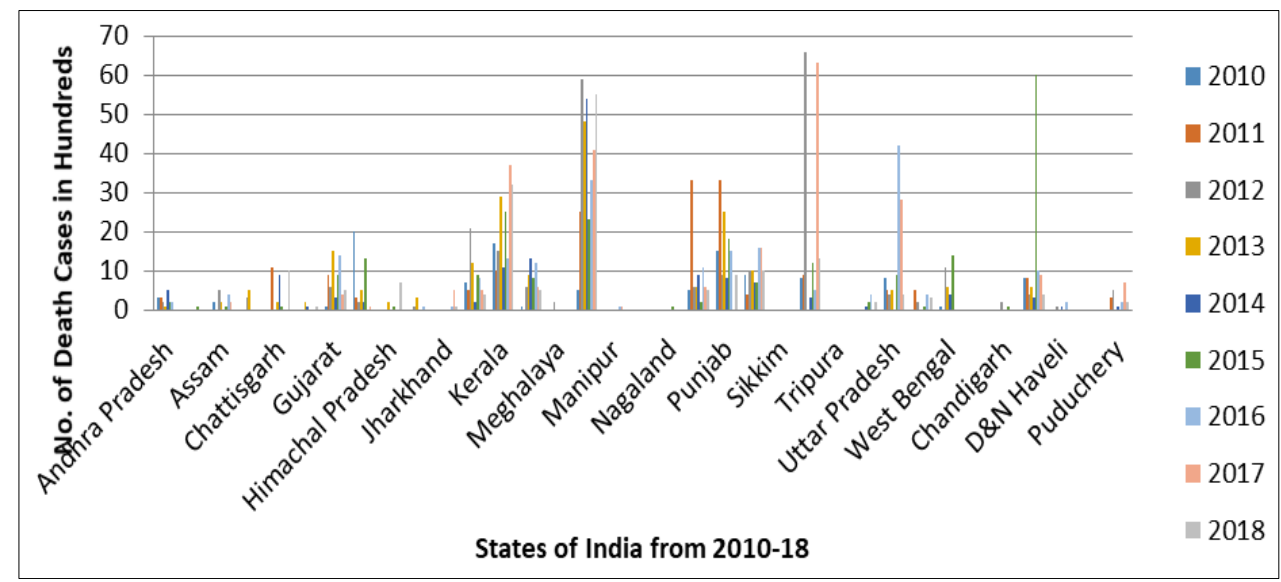

Fig 5: The Total Dengue Death Cases in India from 2010-18, state-wise Distribution

\subsection{Hot spot analysis and spatial interpolation: INDIA} The spatial distribution of dengue cases for India from the year 2013 to 2018 was calculated using IDW. Depending upon the registered number of dengue cases, high and low clustered areas, hotspot and cold spot locations were found to be Karnataka (17018) being the third-highest and Arunachal Pradesh ${ }^{[15]}$ the lowest clustered area in India during the year
2017. However, Karnataka (4427) stood the ninth highest and Arunachal Pradesh (1) stood lowest clustered area in the year 2018. The highest increased number (11570) of dengue cases in Karnataka is observed in the year 2019. Dengue cases are high in the year 2010-2012. Though the cases were constant in the year 2017, the increased number of dengue cases can be observed in the year 2018 (Fig. 6).

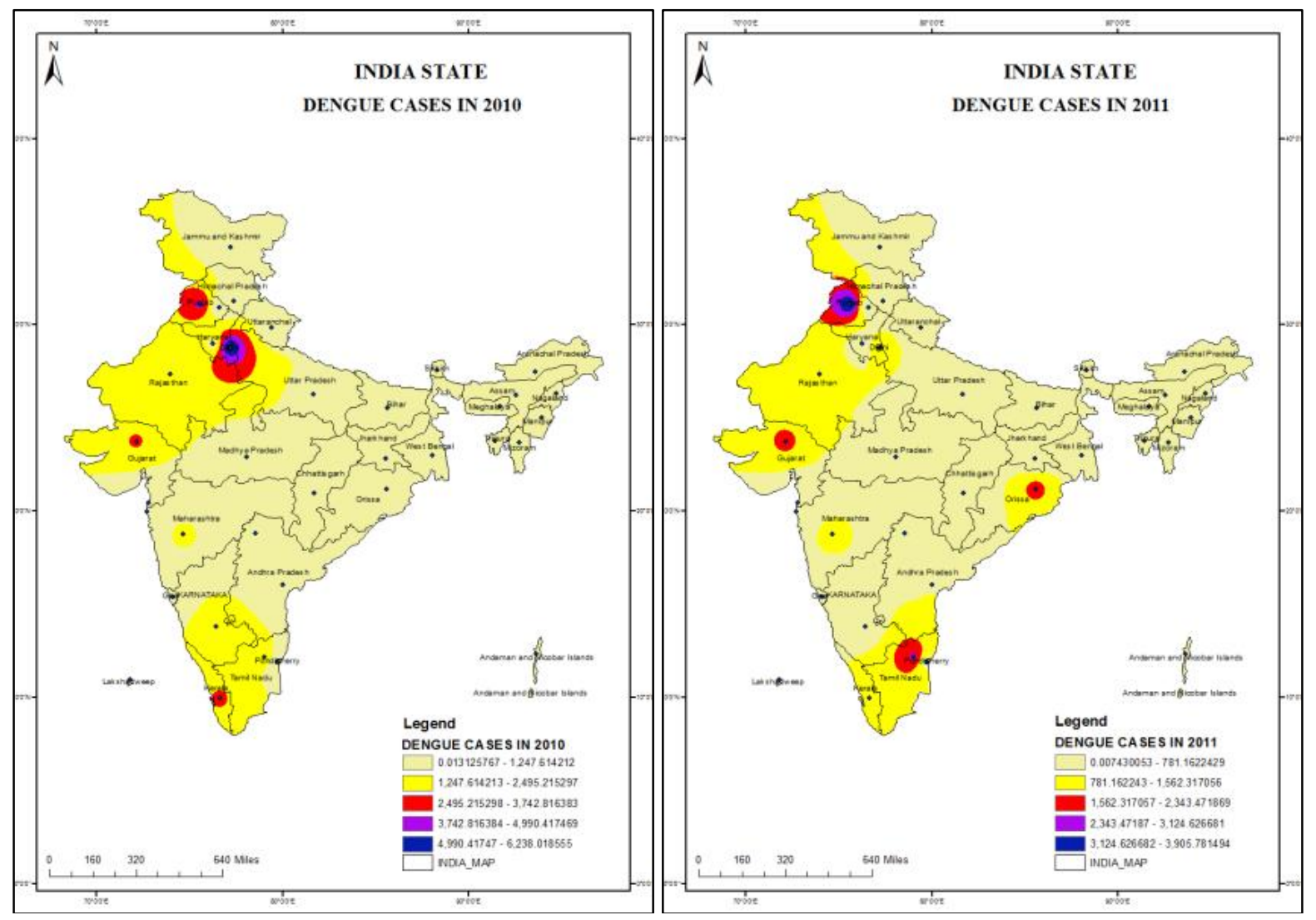



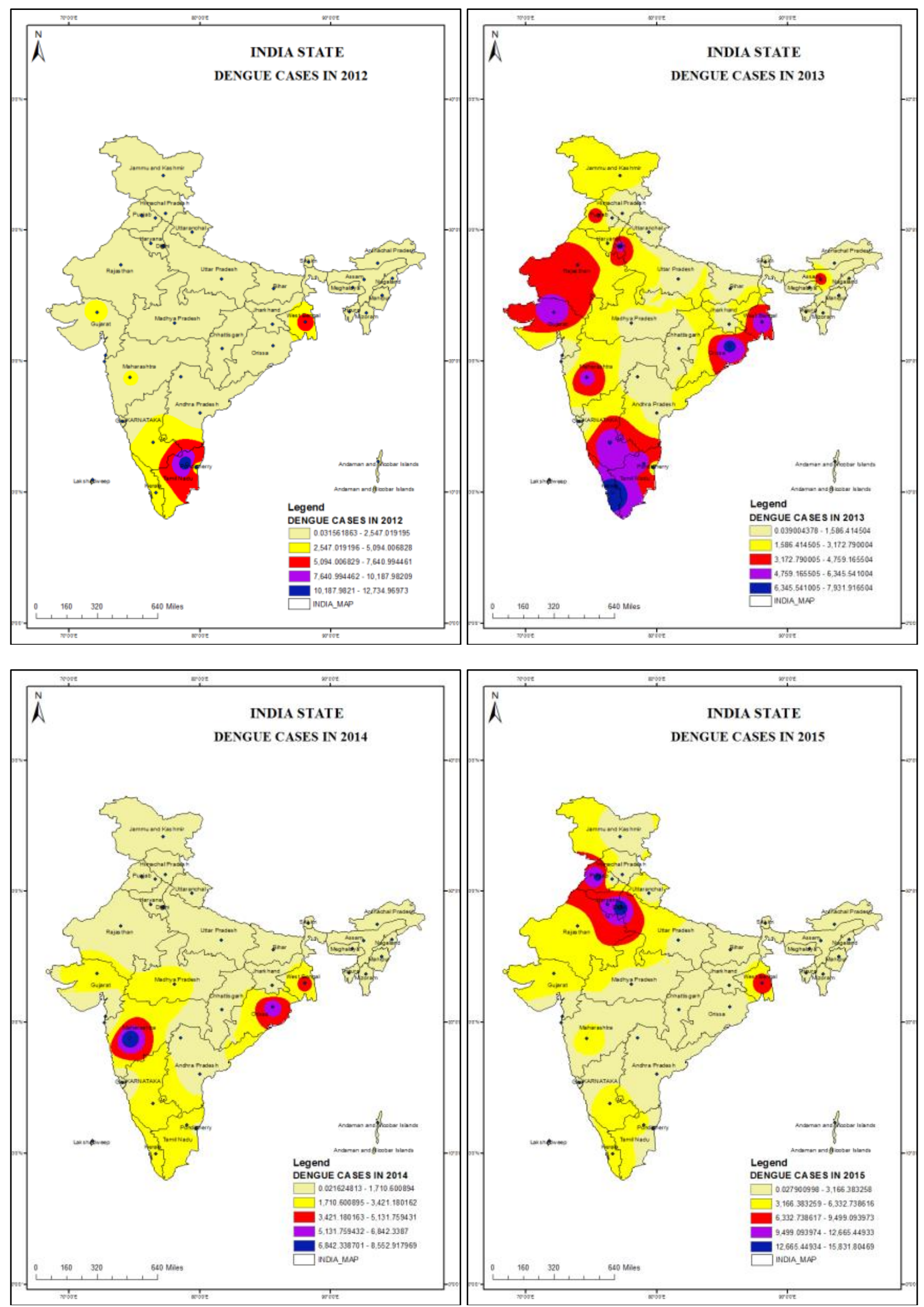

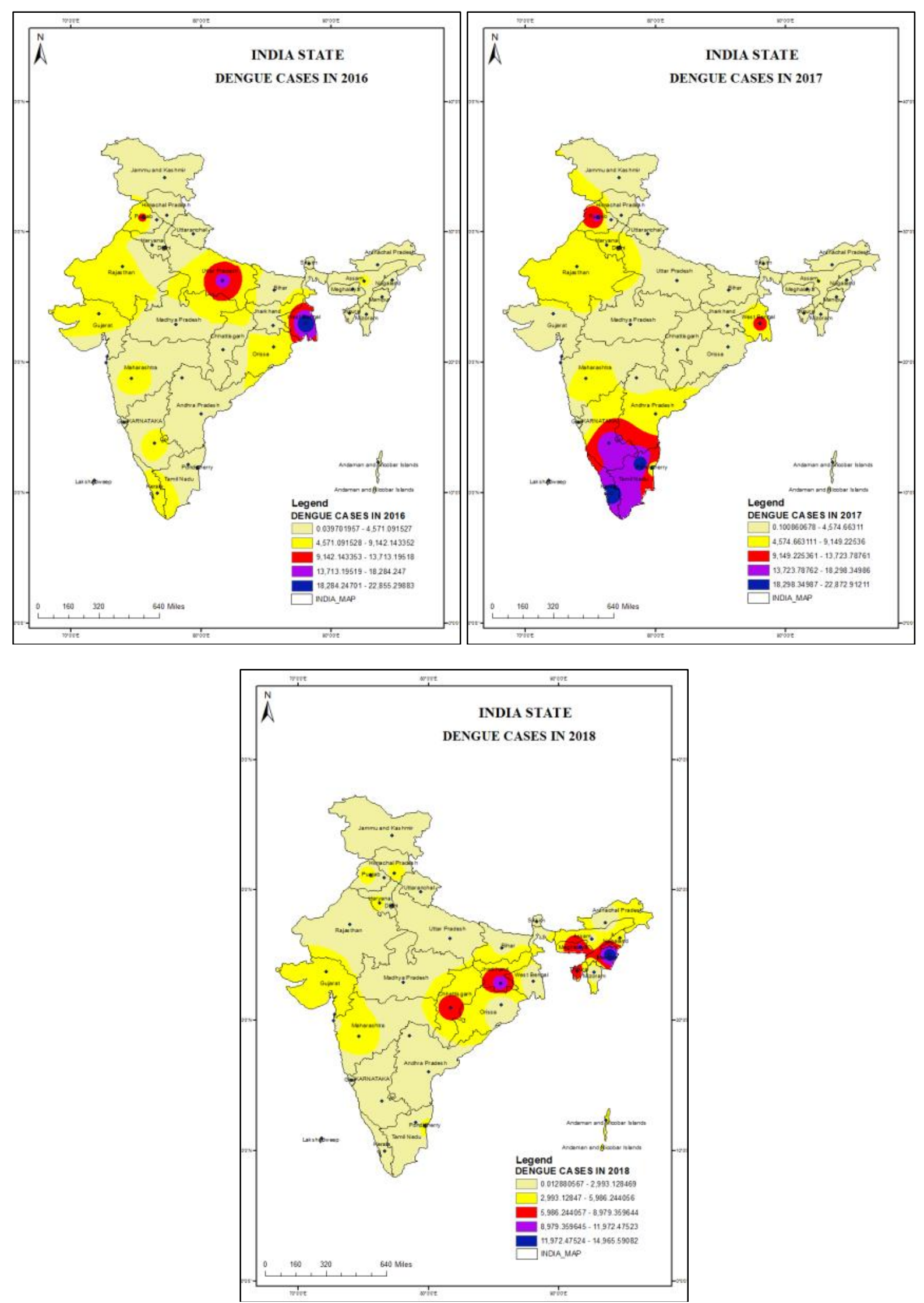

Fig 6: The overall Dengue cases in India from 2010-18 by a IDW interpolation pattern with a Quantile classification.

The epidemiological data displayed 2256 dengue cases that were reported in the Mysore district (taluks, $\mathrm{n}=8$ ) during the period of 2013 to 2018 . The number of positive dengue cases in $2013,2014,2015,2016,2017$, and 2018 was found to be $334,66,382,582,843$ and 49 respectively. The graphical representation of dengue cases, taluk wise distribution in Mysore District from 2013-18 is shown in Fig. 7. The number indicates an increase in dengue cases in the year 2015, 2016, 2017. 


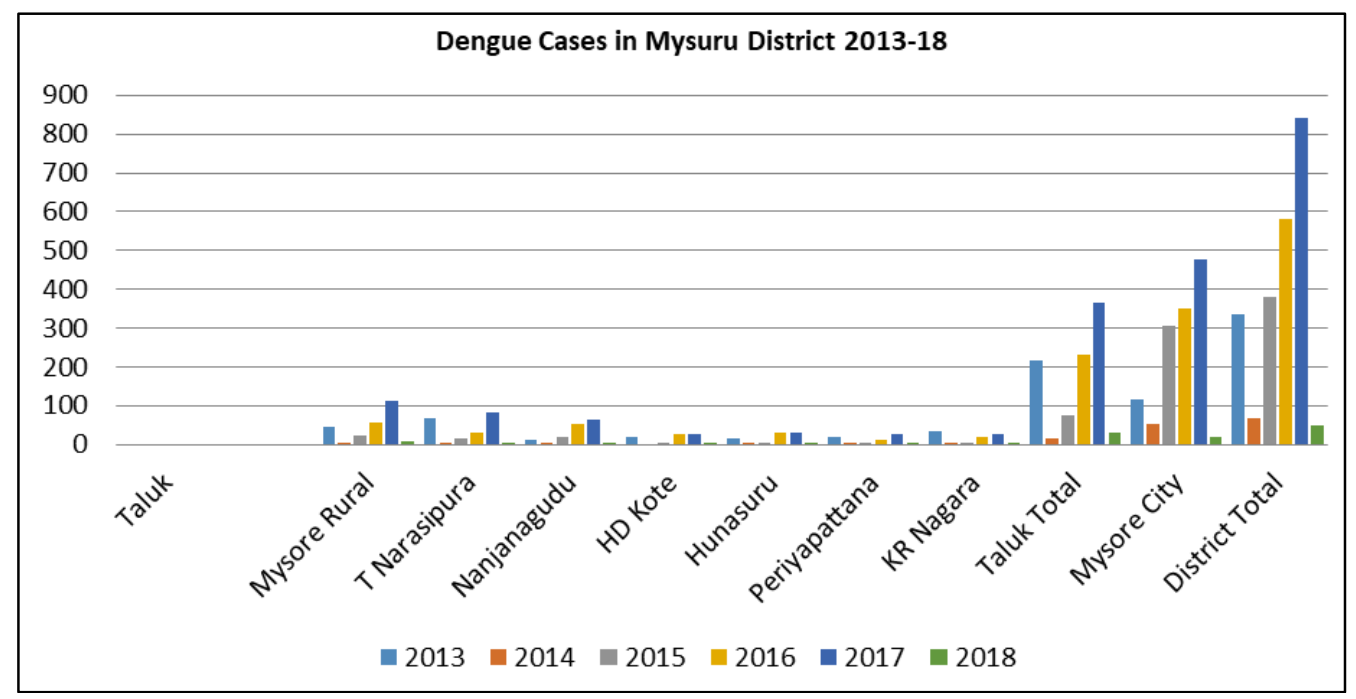

Fig 7: The Total Dengue Positive Cases in Mysore District from 2013-18

The results showed that the majority of the reported dengue cases were in males when compared with the female population (Fig. 8). The data indicates that the dengue fever is predominant is all the age groups $0-14,15-44,45-60$ and above 60 years (Fig. 9). Nevertheless, comparatively age groups 0-14 and 15-44 were mostly affected in all the six years.

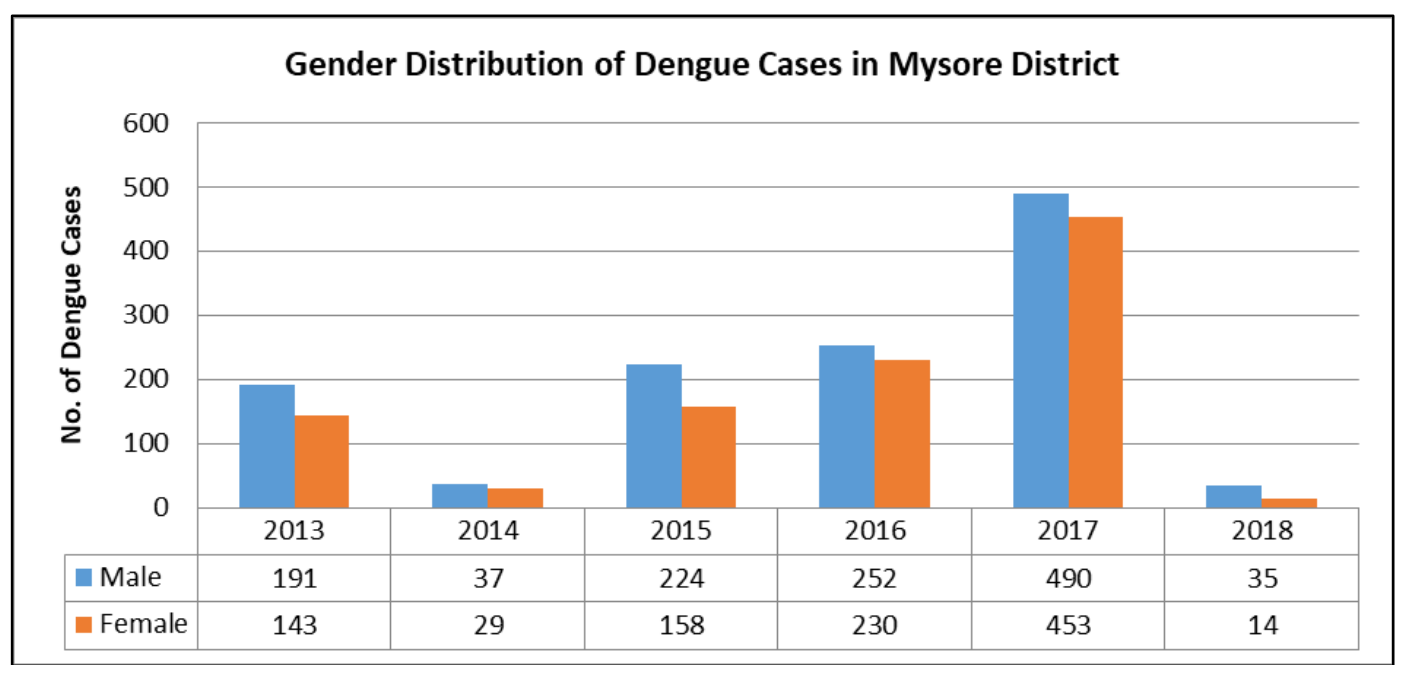

Fig 8: Gender-wise distribution of Dengue Cases in Mysore District from 2013-18

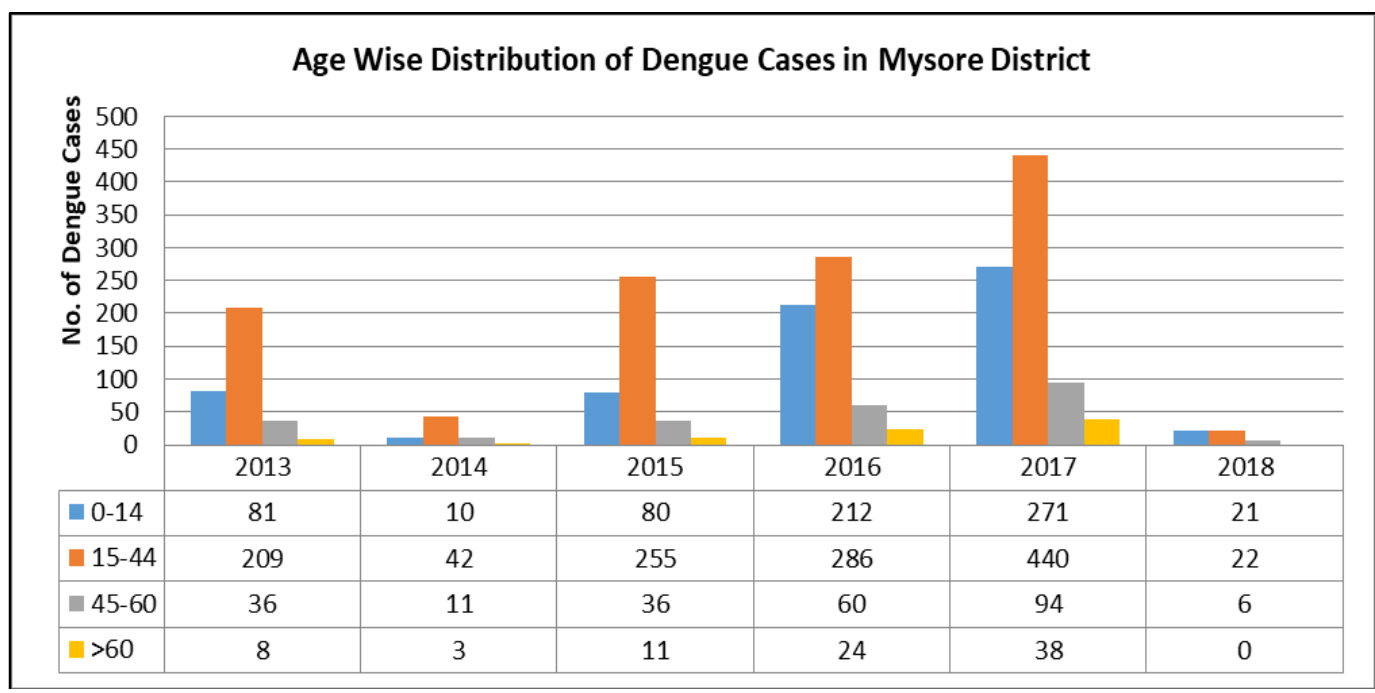

Fig 9: Age-wise distribution of Dengue Cases in Mysore District from 2013-18 


\subsection{Hot spot analysis and spatial interpolation: Mysore}

The localities with high and low clusters of dengue case abundance were identified using Arc GIS, Spatial interpolation tool. In Mysore three hotspot taluks in the year 2017 were identified as 477 cases in Mysore city, 111 cases in Mysore rural and 83 cases in T Narasipura. However, in the year 2018, the cases are reduced, three hotspots were identified as 20 cases in Mysore city, 7 cases in Mysore rural and 5 cases in KR Nagar. As there is a different rate of dengue cases, the hotspot districts showed high standard deviations. Mysore city (477) was found to be the highest in the district during the year 2017 as well as during the year 2018. The lowest clustered area was found to be KR Nagar and HD Kote during the year 2017 and 2018 respectively (Fig. 10).
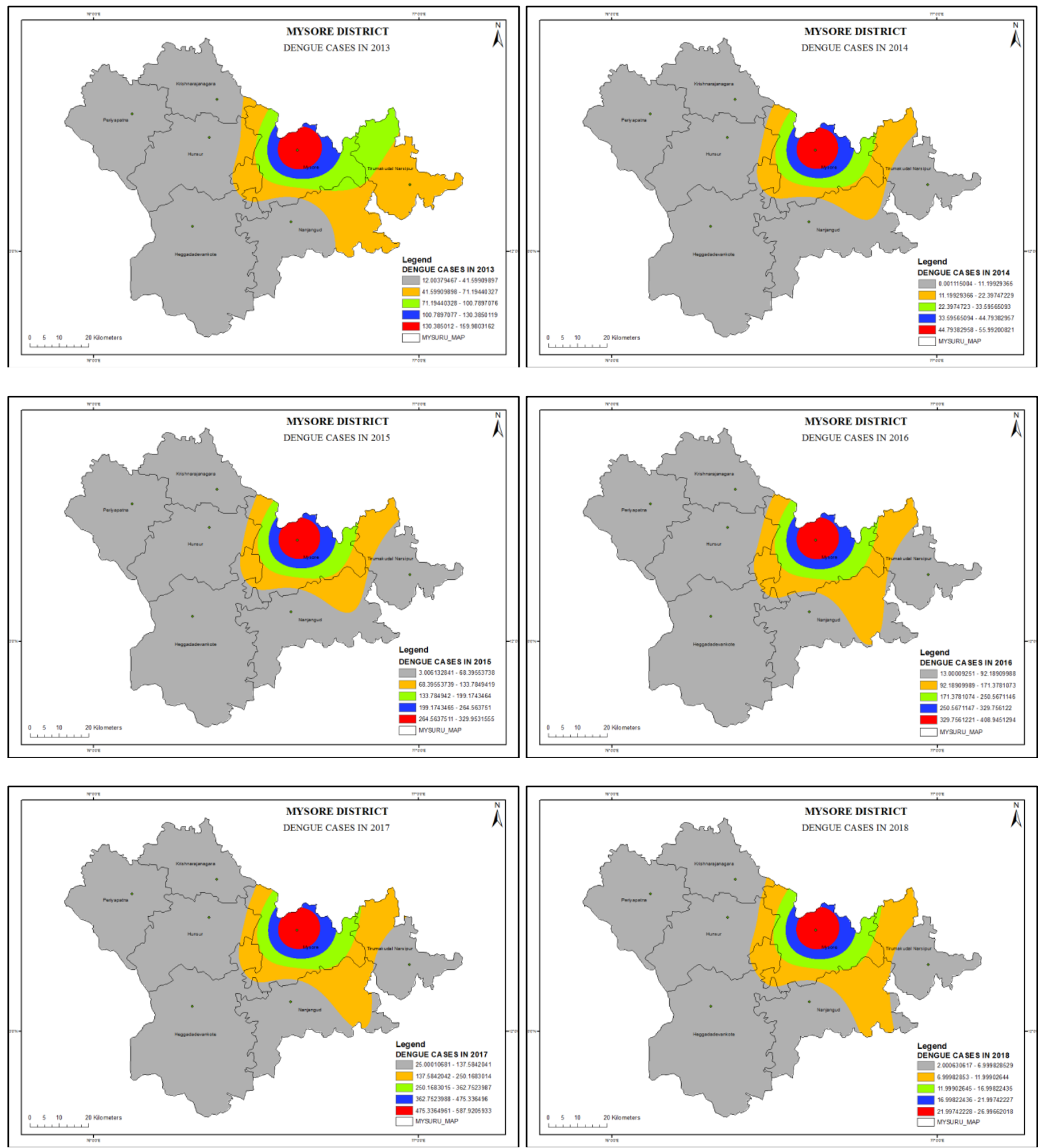

Fig 10: Spatial Distribution of Dengue cases in Mysore District from 2013-18

\subsection{Taluk level pattern of Dengue Cases}

Based on the number of total dengue cases, all taluks $(n=7)$ were grouped into four categories. The spatial distribution of minimum endemic areas, average endemic areas and high endemic areas with reported dengue cases among taluks in Mysore district of Karnataka from 2013 to 2018 is illustrated in the Fig. 11. Mysore city showed as the maximum endemic area during 2013, 2015, 2016, 2017 and 2018. 

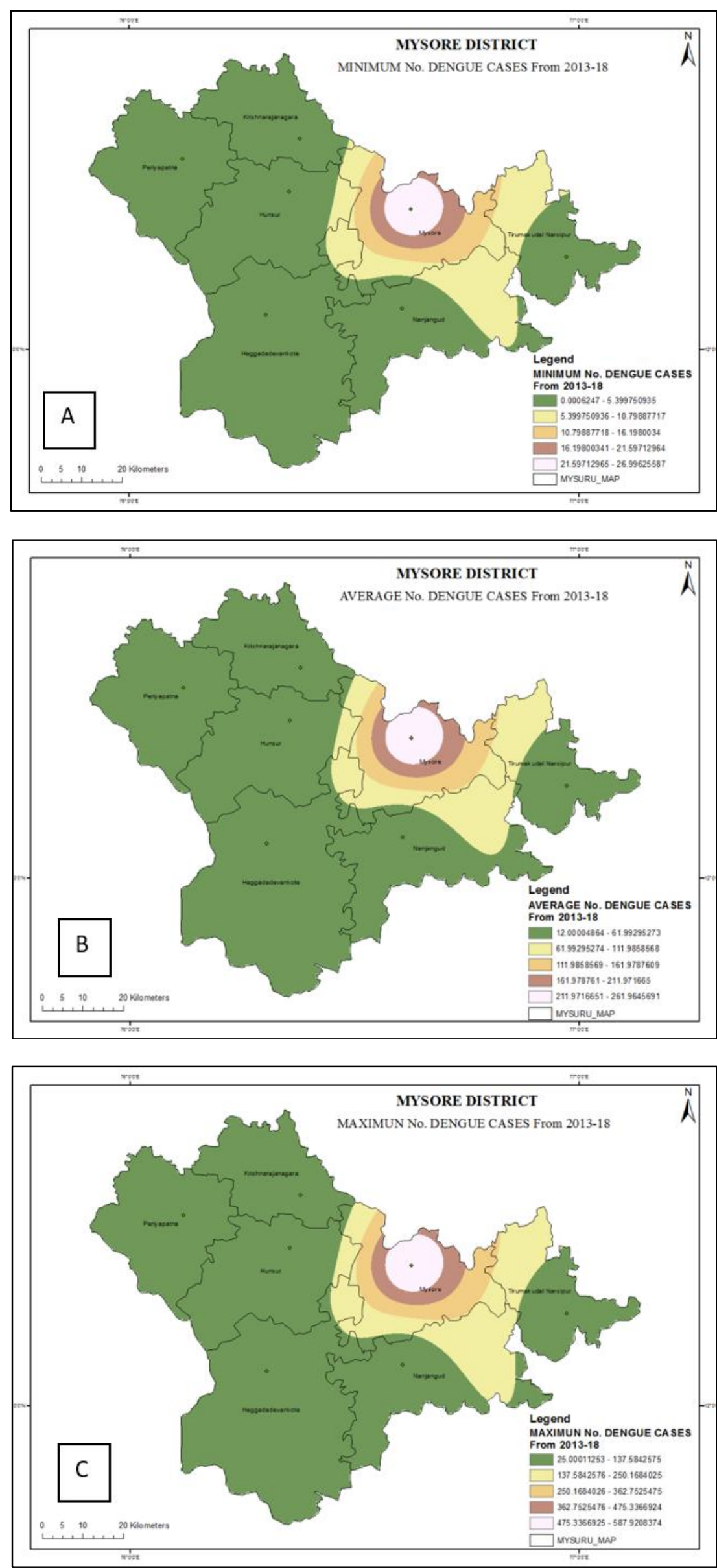

Fig 11: Spatial Distribution of Dengue cases in Mysore District from 2013-18 A) Minimum B) Average C) Maximum 


\subsection{Dengue Cases in Urban and Rural Mysuru}

According to the analysis of data, Mysore urban was found to be the highest number of dengue cases when compared with rural areas (Fig. 12). The death cases due to dengue disease in Mysore urban and rural is illustrated (Fig. 13). The number of dengue cases depends upon proper sanitation, environmental management to detect or eliminate mosquito breeding sources, proper knowledge to common people regarding prevention of disease. Therefore, it is the quality of the surrounding environment that indicates the disease outcome, which can be clearly identified. This study helps public health officials to identify the zones of disease endemics in executing real time decisions for preventive and precautionary strategies to control prevalence of "Dengue-The vector borne" disease effectively.

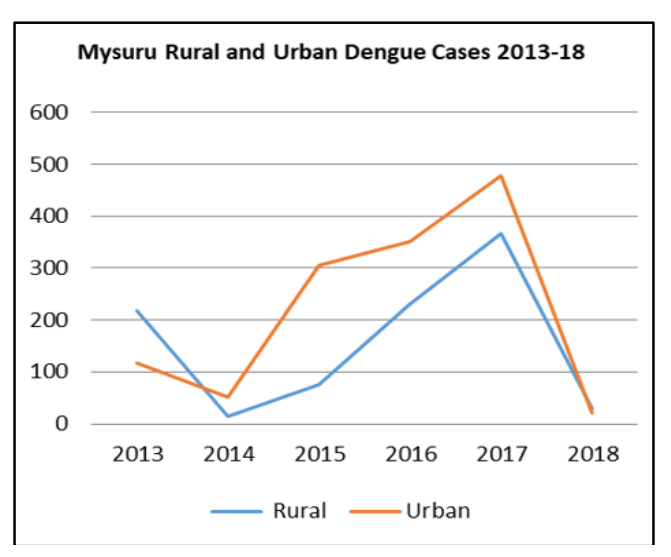

Fig 12: Dengue Positive Cases in Urban and Rural Mysuru from 2013-18

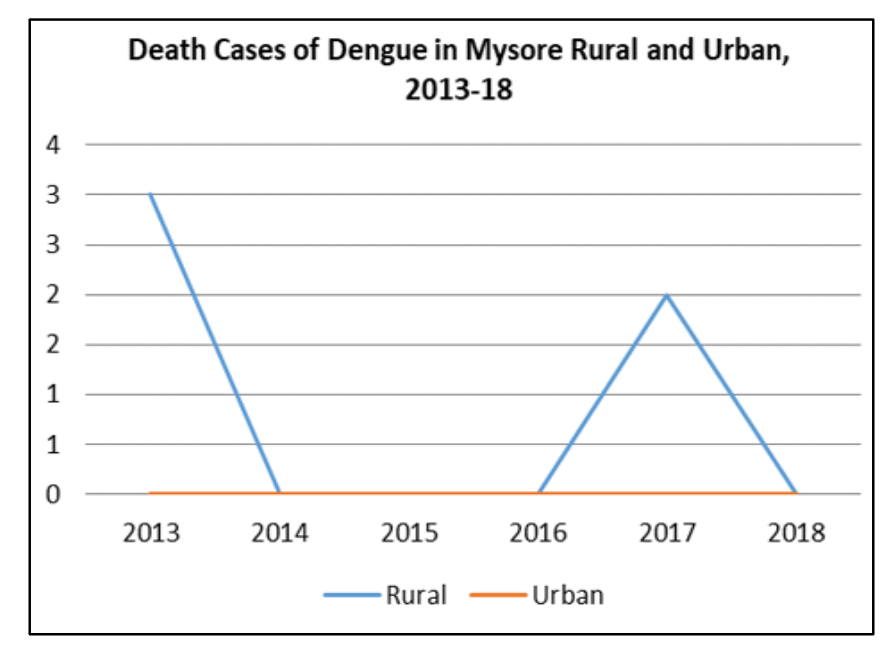

Fig 13: Dengue death Cases in Urban and Rural Mysuru from 2013-18

The study interprets an increased rate of re-emerging dengue cases in Mysore during the year 2017. The dengue death cases in Mysore from 2013 to 2018 are illustrated graphically in Fig. 14.

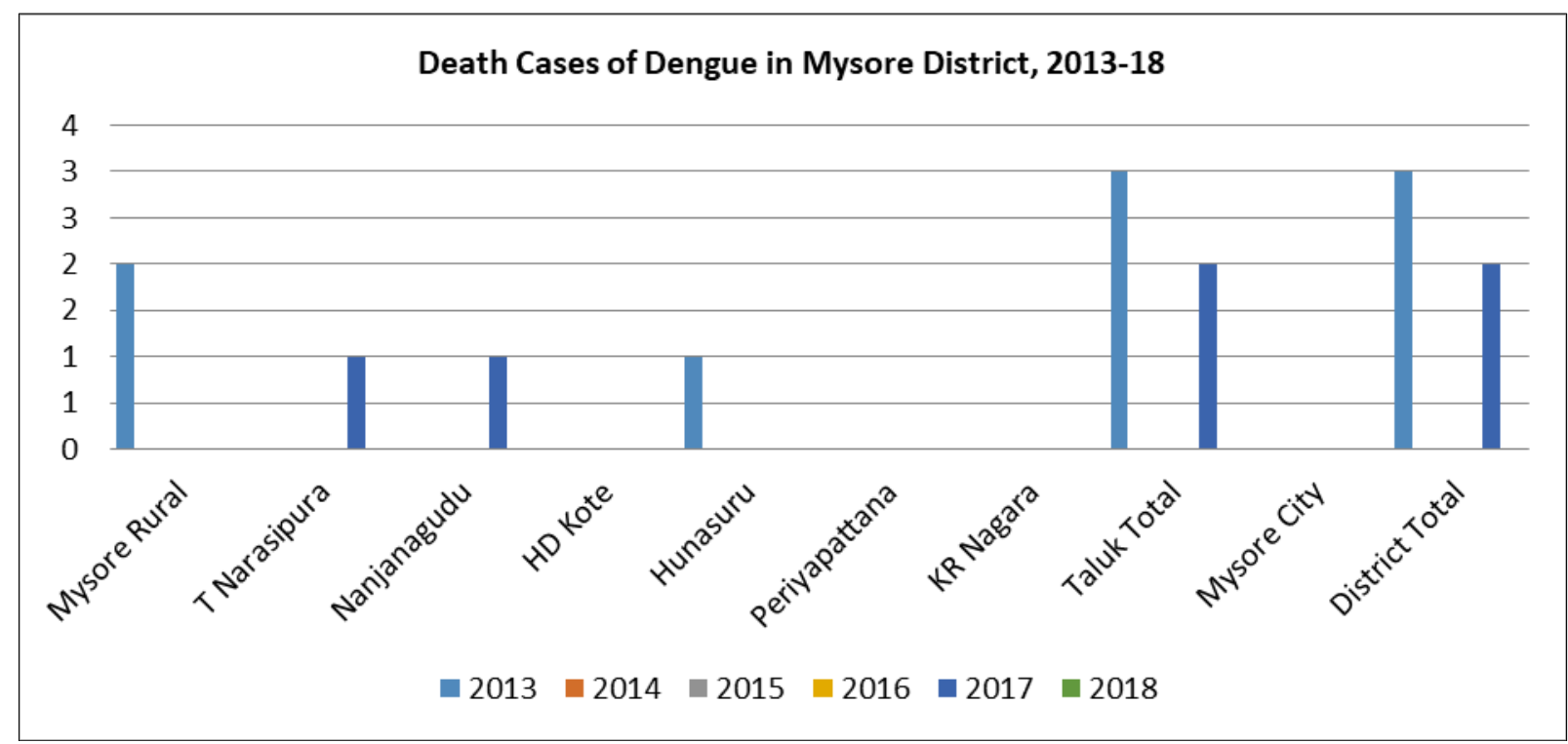

Fig 14: The Total Death Cases of Dengue in Mysuru District from 2013-18, Talukas Wise distribution. The zero death cases can be observed in Periyapattana and KR Nagar. 


\subsection{Rate of increased dengue prevalence pattern in Karnataka}

The epidemiological data shows that in total 2285, 405, 3924, 6408, 3358, 6083, 17018, 4427 and 11570 (till September 2019) reported dengue cases in the year 2010, 2011, 2012, 2013, 2014, 2015, 2016, 2017, 2018 and till September 2019 respectively (Fig. 15). By the data, it indicates re-emergence of dengue disease and fluctuations in its prevalence. The results indicate the importance of understanding the spatial interpolation of dengue incidence to prevent the future risk and complexity of the fast-growing disease.

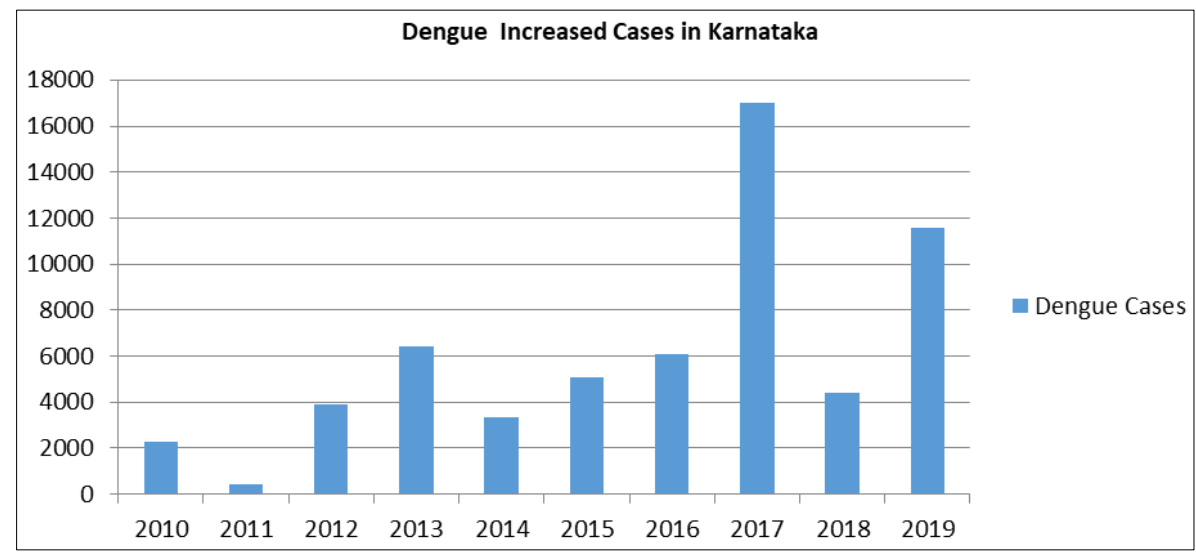

Fig 15: Dengue Pattern in Karnataka from January 2019

\section{Discussion}

The epidemiology and the use of computational geographic information system is a significant challenge for surveillance and effective control of public health. The gradual increase in the dengue cases can be observed in India year by year. Particularly during the year 2017, there is a tremendous increase in the dengue reported cases as well as death. Therefore, knowledge upon the epidemiological status of dengue disease, effective surveillance study, epidemiological data analysis, disease outbreak, hot spot analysis, intensity and spread of the disease is of precarious importance ${ }^{[36]}$.

The prevalence of dengue in India is determined by the comparative study across population density. Many reports suggested that the disease incidence in spatial patterns and highlighted geographical areas would reveal the significant incidence of the disease in a selective area ${ }^{[51]}$. Most of the study has focused on the epidemiological and entomological aspects of dengue ${ }^{[51]}$. This is the first study to estimate the spatial distribution and cluster analysis using IDW tool for dengue disease in Mysuru District and overall dengue cases in India. The similar study, the spatial statistical analysis through geographical information system was used to analyse hot spot regions in the state Andhra Pradesh, India [36]. One of the studies has also reported the prevalence of the different diseases in Karnataka using the tools of geographical information system with the comparative analytical procedure of spatial interpolation ${ }^{[37]}$.

The study revealed that in Mysore district the number of dengue cases reported by males are high when compared with females. However, in the country like South America, both males and females were affected by dengue in an equal ratio [35]. The countries like Philippines, Singapore, Sri Lanka, Cambodia and Malaysia also reported an excess of dengue cases from males of age more than or equal to 15 years [34]. The Spatio-temporal variations in the risk of dengue disease is correlated with the temperature and climatic conditions that support the development of the virus ${ }^{[36]}$.

The use of global measures to understand the spatial pattern, hot spot, spread and intensity of the disease through cluster and quantile predictions has been widely recognized in health science employed in this study. The disease such as TB has been mapped for the measurement of disease intensity, hotspot and spread using GIS tool. The tuberculosis incidence of hotspots in Karnataka was also plotted using GIS software [37]. This study used Arc-GIS (demo version) software to retrospectively map the spatial pattern of reported cases of the disease dengue which aids to identify possible risks area visually for the year 2013 to 2018. The identification of spatial risk areas contributes to understanding the dynamic process of the disease epidemic. In some area, though the duration of the dengue is short, the disease intensity might be stronger, while some of the areas show longer epidemic period, which can be represented as the darkest area showing highest value. By this result pattern, the effective risk that would cause in the future can be strained to be controlled by the attitude of people in destroying Aedes breeding habitats. Distribution pattern of the dengue disease showed the gradually increased values in the same locality however, a sudden lower value in the previous year. Nevertheless, the occurrence of the dengue may be erratic that is appearing continuously, disappearing in some year and might reappear again in the following year.

Regarding the outcome of the study from the year 2013 to 2018 level of dengue IDW pattern using the local and global detection has been represented. The contrasting study to other diseases like tuberculosis in Mysore followed by cases in Karnataka was also reported using GIS software ${ }^{[37]}$. The dengue cases were high in males when compared to females were also analysed and reported from six Asian countries ${ }^{[34]}$. The same method of spatial analysis was also used for cancer incidences that determined to identify hotspots and risk areas in the western regions of Tamil Nadu ${ }^{[38]}$. The infectious disease like malaria in the Kalburgi taluk of Karnataka was taken up to analyse the excess of greatest risk, the hotspot of the disease had been plotted using spatial decision support system ArcGIS ${ }^{[39]}$.

The major findings of this study are first, the notification data for the disease dengue from the recent years that would aid to develop precautionary measures and regulatory procedures to prevent the dengue events in future. Secondly, reported 
dengue cases from all the taluks in Mysore districts followed by overall cases of Karnataka and India are included for the data analysis. Finally, the hot spot analysis using novel spatial distribution and cluster analysis methods were used to determine the hotspots/clusters of the dengue disease. This study enables to develop spatial and temporal maps that would aid public health officials in developing preventive measures towards dengue management.

However, this study does not comprise the local mosquito density data, therefore incompetent to add upon the information to vector control interventions for the disease management. The factors such as climatic changes, socioeconomic conditions and population growth were limited. Nevertheless, the data from the latest six years have been included to bridge the information for future years that would integrate into control of the disease dengue.

\section{Summary and Conclusion}

This study incorporates the application of geographical information system to analyse disease endemic, prevalence, prediction of hotspot and cold spot and spatial spread of dengue disease with respective years. This technique effectively ensures the dengue patterns of Mysore district followed by the overall cases of Karnataka and states of India. The spatial interpolation model for predicting dengue disease intensity using Arc-GIS was the first attempt for Mysore district. This aids in the identification of spatial patterns of dengue disease. This technique significantly ensures the quality of disease prevalence that can be relied on to develop preventive measures by health service provision. The interpolation pattern of the disease can be easily understood by using GIS tools. By this study, the heterogeneity of the dengue disease is observed through spatial patterns within the study region. The GIS-based epidemiological maps for dengue disease in the identified areas are most beneficial for public health care and family welfare regional officers to implement disease preventive strategies in their disease control programme. Despite complemented by numerous methodological limitations, activity space-based spatial analysis delivers a further awareness of dengue transmission dynamics in Mysore city. The effect of this study is still useful in conveying measures to reduce dengue prevalence and for awareness of public health.

\section{Acknowledgements}

Authors are thankful for Dr. Prakash M Halami, Chief Scientist \& Head, Microbiology and Fermentation Technology, CSIR-CFTRI, Mysore for analyzing the manuscript. The authors are thankful to Dr. Chidambaram, District Health and Family Welfare Office, Nazarbad, Mysuru for providing the required data for the study. We extend our gratitude to JSS Academy of Higher Education and Research, Mysuru for the intense support.

\section{Conflict of Interest}

All the authors declare no conflict of interest.

\section{References}

1. Halstead SB. Pathogenesis of dengue: challenges to molecular biology. Science 1988;239(4839):476-81.

2. Mustafa MS, Rasotgi V, Jain S, Gupta V. Discovery of fifth serotype of dengue virus (DENV-5): A new public health dilemma in dengue control. Medical journal armed forces India 2015;71(1):67-70.

3. Kurane I. Dengue hemorrhagic fever with special emphasis on immunopathogenesis. Comparative immunology, microbiology and infectious diseases 2007;30(5-6):329-40.

4. Guzman MG, Halstead SB, Artsob H, Buchy P, Farrar J, Gubler DJ et al. Dengue: a continuing global threat. Nature reviews microbiology 2010;8(12):S7-16.

5. Guzmán MG, Kouri G. Dengue: an update. The Lancet infectious diseases 2002;2(1):33-42.

6. Balmaseda A, Hammond SN, Pérez L, Tellez Y, Saborío SI, Mercado JC et al. Serotype-specific differences in clinical manifestations of dengue. The American journal of tropical medicine and hygiene 2006;74(3):449-56.

7. Karamchandani PV. Dengue group of fevers in India. Lancet 1946;1(6386):92. doi:10.1016/s01406736(46)91229-9

8. World Health Organization. Dengue and severe dengue. World Health Organization. Regional Office for the Eastern Mediterranean, 2014.

9. National Vector Borne Disease Control Programme (annual report). Director General of Health Services, Ministry of Health \& Family Welfare, Government of India.

10. Gupta N, Srivastava S, Jain A, Chaturvedi U. Dengue in India. The Indian journal of medical research 2012;136(3):373-90.

11. Tripathi P, Kumar R, Tripathi S, Tambe JJ, Venkatesh V. Descriptive epidemiology of dengue transmission in Uttar Pradesh. Indian pediatrics 2008;45(4):315.

12. Ali M, Wagatsuma $Y$, Emch M, Breiman RF. Use of a geographic information system for defining spatial risk for dengue transmission in Bangladesh: role for Aedes albopictus in an urban outbreak. The American journal of tropical medicine and hygiene 2003;69(6):634-40.

13. Wen TH, Lin NH, Chao DY, Hwang KP, Kan CC, Lin $\mathrm{KC}$ et al. Spatial-temporal patterns of dengue in areas at risk of dengue hemorrhagic fever in Kaohsiung, Taiwan, 2002. International Journal of Infectious Diseases 2010;14(4):e334-43.

14. Andianasolo H, Bohra A. Apllication of GIS in Modelling of Dengue Risk Based on Socio-Cultural data: Case of Jalor, Rajasthan, India. In22nd Asian Conference on Remote Sensing., Singapore Institute of Surveyors and Valuers (SISV), 2001.

15. Noraishah MS, Krishnarajah I. Use of GIS Mapping for HFMD Cases in Sarawak, Malaysia. International Journal 2016;5(10):1937-45.

16. Nakhapakorn K, Jirakajohnkool S. Temporal and spatial autocorrelation statistics of dengue fever. WHO Regional Office for South-East Asia 2006;30:177-183.

17. Gubler DJ, Meltzer M. Impact of dengue/dengue hemorrhagic fever on the developing world. InAdvances in virus research 1999;53:35-70.

18. Duncombe J, Clements A, Hu W, Weinstein P, Ritchie S, Espino FE. Geographical information systems for dengue surveillance. The American journal of tropical medicine and hygiene 2012;86(5):753-5.

19. Jones SG, Kulldorff M. Influence of spatial resolution on space-time disease cluster detection. PLoS One 2012;7(10):e48036.

20. Bhunia GS, Kesari S, Chatterjee N, Kumar V, Das P. Spatial and temporal variation and hotspot detection of 
kala-azar disease in Vaishali district (Bihar), India. BMC infectious diseases 2013;13(1):64.

21. Lai PC, So FM, Chan KW. Spatial epidemiological approaches in disease mapping and analysis. CRC press 2008;1:194.

22. Getis A, Ord JK. The analysis of spatial association by use of distance statistics. InPerspectives on spatial data analysis Springer, Berlin, Heidelberg, 2010, 127-145.

23. Ord JK, Getis A. Local spatial autocorrelation statistics: distributional issues and an application. Geographical analysis 1995;27(4):286-306.

24. Moran PA. Notes on continuous stochastic phenomena. Biometrika 1950;37(1, 2):17-23.

25. Graham AJ, Atkinson PM, Danson FM. Spatial analysis for epidemiology. Acta Tropica 2004;91(3):219-225.

26. Getis A Cliff, ad and ord, jk 1973: Spatial autocorrelation. london: Pion. Progress in Human Geography 1995;19(2):245-9.

27. Cli AD, Ord VK. Spatial processes: models and applications, Pion, London. The Department of Environment Transport Regions (2000) Public Private Partnership for National Air, 1981.

28. Overmars KD, De Koning GH, Veldkamp A. Spatial autocorrelation in multi-scale land use models. Ecological modelling 2003;164(2, 3):257-70.

29. Goodchild MF. What problem? Spatial autocorrelation and geographic information science. Geographical analysis 2009;41(4):411-7.

30. Zhang C, McGrath D. Geostatistical and GIS analyses on soil organic carbon concentrations in grassland of southeastern Ireland from two different periods. Geoderma 2004;119(3, 4):261-75.

31. Legendre P, Fortin MJ. Spatial pattern and ecological analysis. Vegetatio 1989;80(2):107-38.

32. Chaosheng Z, Shu T, Guiping Y, Shui L. Spatial Autocorrelation Analysis of Trace Element Contents of Soil in Tianjin Plain Area [J]. Acta Pedologica Sinica 1995;1(32):50-57.

33. Zhang C, Zhang S, He J. Spatial distribution characteristics of heavy metals in the sediments of Changjiang River System-Spatial autocorrelation and fractal methods. Acta Geographica Sinica-Chinese Edition 1998;53:87- 95.

34. Anker M, Arima Y. Male-female differences in the number of reported incident dengue fever cases in six Asian countries. Western Pacific surveillance and response journal: WPSAR 2011;2(2):17.

35. Chakravarti A, Roy P, Malik S, Siddiqui O, Thakur P. A study on gender-related differences in laboratory characteristics of dengue fever. Indian journal of medical microbiology 2016;34(1):82.

36. Mutheneni SR, Morse AP, Caminade C, Upadhyayula SM. Dengue burden in India: recent trends and importance of climatic parameters. Emerging microbes \& infections 2017;6(1):1-0.

37. Talluri Rameshwari KR, Rani RN, Sunila, Ravi Kumar M, Sumana K. A comparative analysis of spatial interpolation incidence of tuberculosis prevalence in Karnataka. International Journal of Scientific Research in Science and Technology 2017;8(3):964-975.

38. Harathi PB, Selvaraj J, Devi MP, Valarmathi S, Balasubramanian S. Spatial Analysis of Cancer Incidences to Identify Risk Areas and Hot Spots: A Case
Study in the Western Regions of Tamil Nadu, India. International Journal of Scientific Research 2014;3(7):2277-8179

39. Shekhar S, Yoo EH, Ahmed SA, Haining R, Kadannolly $\mathrm{S}$. Analysing malaria incidence at the small area level for developing a spatial decision support system: a case study in Kalaburagi, Karnataka, India. Spatial and spatiotemporal epidemiology 2017;20:9-25.

40. Chakravarti A, Arora R, Luxemburger C. Fifty years of dengue in India. Transactions of the Royal Society of Tropical Medicine and Hygiene 2012;106(5):273-82.

41. World Health Organization. Global strategy for dengue prevention and control 2012-2020.

42. Toan DT, Hoat LN, Hu W, Wright P, Martens P. Risk factors associated with an outbreak of dengue fever/dengue haemorrhagic fever in Hanoi, Vietnam. Epidemiology \& Infection 2015;143(8):1594-8.

43. Saxena R, Nagpal BN, Das MK, Srivastava A, Gupta SK, Kumar A et al. A spatial statistical approach to analyze malaria situation at micro level for priority control in Ranchi district, Jharkhand. The Indian journal of medical research 2012;136(5):776.

44. Weaver SC, Vasilakis N. Molecular evolution of dengue viruses: contributions of phylogenetics to understanding the history and epidemiology of the preeminent arboviral disease. Infection, genetics and evolution. 2009;9(4):52340.

45. Vesanto J, Alhoniemi E. Clustering of the self-organizing map. IEEE Transactions on neural networks 2000;11(3):586-600.

46. Shepard DS, Undurraga EA, Halasa YA. Economic and disease burden of dengue in Southeast Asia. PLoS Negl Trop Dis 2013;7(2):e2055.

47. Valkonen VP, Kolehmainen M, Lakka HM, Salonen JT. Insulin resistance syndrome revisited: application of selforganizing maps. International journal of epidemiology. 2002;31(4):864-71.

48. World Health Organization. Comprehensive guideline for prevention and control of dengue and dengue haemorrhagic fever- revised and expanded edition. WHO Regional office for South East Asia (WHO-SEARO), New Delhi xiv-196.

49. World Health Organization T. Dengue: guidelines for diagnosis, treatment, prevention and control. Geneva: WHO Library, 2009, 10-2.

50. Tipayamongkholgul M, Lisakulruk S. Socio-geographical factors in vulnerability to dengue in Thai villages: a spatial regression analysis. Geospatial health 2011;5(2):191-8.

51. Hanson CE, Wieczorek WF. Alcohol mortality: a comparison of spatial clustering methods. Social Science \& Medicine 2002;55(5):791-802. 